\title{
Das relações intersemióticas: Robinson Crusoe divisando fronteiras da literatura ao cinema brasileiro
}

\author{
José David Borges Júnior ${ }^{1}$
}

\begin{abstract}
RESUMO: A presente pesquisa busca, à luz da tradução intersemiótica e das relações intertextuais, comparar o clássico da literatura universal Robinson Crusoe (1719), de Daniel Defoe, com a transposição filmica intitulada As aventuras de Robinson Crusoé (1978), sob a direção de Mozael Silveira. Nessa ordem, pretende-se demonstrar como o problema da fidelidade absoluta ao texto fonte é superado pela apropriação criativa e reelaboração paródica promovida pelo realizador da adaptação.
\end{abstract}

ABSTRACT: This research aims, in the light of intersemiotic translation and intertextual relations, to compare the classic of universal literature Robinson Crusoe (1719), by Daniel Defoe, with the transposition film entitled As aventuras de Robinson Crusoé (1978), under the direction of Mozael Silveira. In that order, intended to demonstrate how the problem of absolute fidelity to the text source is outweighed by the creative appropriation and reworking by director promoted parodic adaptation.

PALAVRAS-CHAVE: relações intersemióticas; paródia; literatura infanto-juvenil; cinema brasileiro; leitura.

KEYWORDS: intersemiotic relations; parody; literature for youth people; Brazilian cinema; reading.

\section{Nota introdutória}

Esta pesquisa pretende, pelas vias dos estudos comparados, da tradução intersemiótica e das relações intertextuais, realizar uma

\footnotetext{
1 Mestrando no programa de Pós-Graduação em Estudos Comparados de Literaturas de Língua Portuguesa, Departamento de Letras Clássicas e Vernáculas - FFLCH - USP. Pesquisa: A literatura para crianças e jovens nas veredas do cinema. E-mail: davidjunior@usp.br
} 
análise acerca do romance Robinson Crusoe (1719), do escritor e jornalista inglês Daniel Defoe, procurando enfatizar os diálogos estabelecidos entre a referida obra e o cinema brasileiro. Para tanto, selecionamos, no campo cinematográfico, a adaptação realizada por Mozael Silveira, intitulada As aventuras de Robinson Crusoé (1978).

Desse modo, com a finalidade de adentrar o terreno das relações intersemióticas, utilizamos estudos como os de Plaza (2000), Stam (2008), Sousa (2001) e Bello (2001), tendo em vista que os mencionados teóricos adotam perspectivas distintas para a conceituação sobre a transposição fílmica, o que nos forneceu rico material para explorar, com segurança, o processo que envolve os diálogos estabelecidos entre literatura e cinema.

Ademais, acreditando que o ato de adaptar uma obra literária para o cinema é, em primeira instância, um exercício de (re)leitura(s) do texto fonte, buscamos elucidar a problemática referente à fidelidade ao texto dito original, descortinando a preconceituosa prática de juízo de valor em relação ao produto filmico fruto da adaptação; isto é, não buscamos priorizar a arte literária em detrimento da arte de fazer cinema ou vice-versa, subjugando este último a um status de dependência ou subserviência cultural àquela, o que denotaria uma hierarquia injusta porque ambos são campos estéticos que lidam com gramáticas que os aproximam, uma vez que pretendem contar estórias, ou seja, estão imersos no universo dos elementos estruturais da narrativa.

Assim, no processo de transposição de uma obra literária para o campo narrativo cinematográfico, o realizador dispõe de vários recursos para a construção de semioses múltiplas. Cabe, então, à mente criativa e realizadora, escolher os recursos que mais lhe interessam para dar conta de alinhavar os fios heterogêneos da estória e, em termos literários, reconfigurá-la no campo do cinema, considerando os sentidos e ideologias que tal realizador pretendeu produzir, isto é, sua subjetividade. Mais adiante verificaremos as escolhas realizadas por Mozael Silveira na construção do seu Robinson Crusoé. 
Dessa maneira, a adaptação se apresenta como prática frutífera no que concerne ao aclaramento de questões mais amplas ${ }^{2}$, haja vista que tal exercício ilumina leituras, isto é, tanto a obra dita original, quanto o filme fruto da adaptação interrogam-se, reciprocamente, proporcionando novas linhas de interpretação para o clássico em relevo.

Nessa ordem de ideias, como veremos mais adiante, o cinema não presta um desserviço à literatura, como apontam alguns teóricos; ao contrário, ambos alimentam-se da mesma fonte: a narrativa. Assim, o filme, produto de uma adaptação - e de uma leitura subjetiva, portanto -, renova essa mesma literatura e, por sua vez, o interesse dos jovens leitores, que passam a explorar, em todas as suas potencialidades estéticas e éticas, o texto literário.

\section{Literatura e cinema: uma questão de fidelidade?}

Sabe-se que o cinema, desde seus primórdios, encontrou na literatura um campo fértil para suprir sua sede por novas estórias, que foram, por sua vez, recontadas na grande tela. Todavia, tal processo não seguiu um movimento de mão única, isto é, se

[...] num primeiro momento, é o cinema, regime de imagens-movimento, que recorre ao texto literário em busca de uma forma narrativa, mais tarde é a literatura que toma emprestado ao cinema procedimentos e temas que modificariam a sua estrutura narrativa. (GUIMARÃES, 1997, p. 109).

Assim, estaria estabelecido um processo dialógico que promove leituras labirinticas e que, como aponta o referido teórico, equacionou os dois campos narrativos em uma espécie de disputa sempre enfatizada pelo argumento de que o cinema, ao adaptar o texto literário,

\footnotetext{
Entendendo como questões mais amplas toda a discussão política, social e cultural que subjaz dos objetos estéticos constantes de nosso corpus.
} 
perde muito em termos de literariedade, massificando o que seria entendido pela alta cultura como arte sacralizada.

Entretanto, como dito anteriormente, acreditamos que o cinema não presta um desserviço à literatura, uma vez que esta passou a configurar, em suas técnicas de produção, diversas especificidades cinematográficas em meio ao referido movimento dialógico. Um bom exemplo para o fenômeno seria a obra A maior flor do mundo (2001), do renomado escritor português José Saramago. O referido texto, dotado de linguagem verbo-visual (palavra e imagem-ilustração), encapsula, em suas técnicas de produção, movimentos de câmera e efeitos óticos próprios da gramática cinematográfica, que exigem um leitor apto a navegar pelo intrincado labirinto de semioses múltiplas, códigos e linguagens híbridas que tal objeto artístico inaugura.

Nesse sentido, a crítica encontra, atualmente, maior aproveitamento na discussão concernente às especificidades de um campo e de outro, e tal atitude não deixa de considerar questões de mercado. Afinal, o prestígio estético de uma determinada obra literária caso do clássico Robinson Crusoe, que conta com uma infinidade de adaptações para o cinema -, sugere sua ampla disseminação e consumo, sendo então um dos critérios de escolha por parte do realizador da adaptação. Todavia, não é o único, pois é possivel observar que os chamados best-sellers também sugerem, ao cineasta, um campo proficuo para a vendagem do produto final adaptado.

Nessa ordem de ideias, o cinema se vende ao adaptar textos literários de grande renome e/ou de ampla disseminação e consumo e, concomitantemente, a literatura que circula também na grande tela absorve uma larga fatia do mercado para o seu consumo, tendo em vista a potencialidade da sétima arte enquanto poderoso veículo de circulação entre as massas em termos até, poderíamos dizer, globais.

Assim, o que está em pauta não é o que antes se afigurava a respeito do cinema, isto é, um cinema que era entendido como uma espécie de diluente e massificador da estética literária canônica. Nestes termos, qual seria então o objetivo de discutir sobre a questão da 
fidelidade absoluta ou traição ao original, uma vez que a teoria literária e a gramática cinematográfica se aproximam, considerando os elementos estruturais da narrativa? Ora, se a transposição fílmica fosse, simplesmente, um ato de fidelidade absoluta de um texto que migra de um meio a outro, teria sentido seguir outra vertente diversa de tal fidelidade?

Todavia, não se pode entender o processo de adaptação cinematográfica por uma chave tão simplista de análise; isto é, o procedimento é complexo, transtextual, e envolve o entrelaçar da multiplicidade de códigos e linguagens que compõem tanto a literatura, quanto o cinema em novas malhas discursivas, tessituras estéticas na convergência de semioses múltiplas.

Nesse sentido, o processo de adaptação denota movimento e "transmutação estético-semiótica efectuada no âmbito das matérias expressivas heterogêneas, sendo, por essa razão, de natureza interartística e transestética [...]." (SOUSA, 2001, p. 25). Ademais, "adaptações filmicas caem no contínuo redemoinho das transformações e referências intertextuais, de textos que geram outros textos num interminável processo de reciclagem, transformação e transmutação.” (STAM, 2008, p. 22).

Além do referido, não se pode deixar de considerar a adaptação como um fenômeno subjetivo, porque pressupõe (re)leitura(s) por parte do realizador, haja vista que "[...] o cinema não filma livros [...] Filmará antes, condicionado por fenômenos de natureza hilética da sétima arte, o que a individualidade de quem adapta, sujeito marcado por imposições históricas e dominantes, lerá.” (SOUSA, p. 27-28).

Diante disso, fica evidenciado que a fidelidade absoluta é, de certo modo, impossivel para o cineasta, tendo em consideração que, dispondo de técnicas divergentes das utilizadas na composição do tecido literário, o artista-adaptador que tentar alcançar tal objetivo (a fidelidade absoluta), ou estará fadado ao fracasso, ou produzirá uma obra literalmente fechada e empobrecedora da estética literária vigente no texto que lhe serviu de matriz. Dai a crítica ter alicerçado, por tanto 
tempo, o julgamento do valor estético-cultural de determinada obra adaptada seguindo o critério da fidelidade como método avaliativo de gradientes estéticos.

Acreditamos, pois, que o texto adaptado para a grande tela é obra autônoma, haja vista que o artista-adaptador tem certa liberdade expressiva para compor - pelo seu talento, criatividade, maleabilidade, enfim, pela forma com a qual lida com a plasticidade do texto literário um objeto novo, pleno e independente; e, nesse sentido, detentor de seus próprios valores estético-culturais por tratar-se de outra obra em outro contexto sociopolítico e cultural.

Vale destacar que não estamos fazendo apologia a um processo adaptativo que tenha como prerrogativa a anarquia da infidelidade absoluta, pois tal atitude, antagônica à anteriormente apresentada, também constituiria um problema para adaptações que se pretendam eficientes. O que nos interessa é marcar, como coeficiente de transposição, uma prática que não tenha por prioridade a fidelidade absoluta, nem a sua antagônica infidelidade total, tendo em vista que isso implicaria o deslocamento de nosso estudo para outro campo, uma vez que a obra adaptada que pretenda seguir um parâmetro de infidelidade total, já não é mais uma adaptação, e sim alusão ao texto literário que lhe serviu de inspiração.

Dito de outro modo, o que buscamos é priorizar o equilíbrio entre a fidelidade absoluta e a anarquia da infidelidade total, isto é, consideramos que o coeficiente de transposição fílmica deva seguir o referido equilíbrio, ora tendendo para um lado da questão, ora para o outro, porém, nunca estático. Assim, a fidelidade é, para nós, um critério importante até o ponto em que trata da absorção das estruturas profundas do texto literário que servirá de base para a adaptação. Contudo, vale ressaltar, não deve servir de encarceramento para criatividade do artista-adaptador.

Por fim, acreditamos que ao adaptar o clássico da literatura universal Robinson Crusoe, Mozael Silveira o fez de uma maneira única e imbuída em aspectos de brasilidade, enquanto Defoe o fez de modo a 
inserir, na constituição estética do texto, um retrato da sociedade burguesa que se consolidava na Inglaterra do século XVIII. Sociedade essa permeada pelo regime escravocrata, como observado através das relações que se estabeleceram entre o herói Crusoe e Friday; e, ainda, na metáfora da própria ilha deserta, apontada por muitos teóricos como uma reprodução da sociedade escravagista e anti-democrática.

Contudo, algumas questões acerca do alcance político, que Defoe propõe em seu romance, permanecem obscurecidas por leituras cristalizadas. Assim, acreditamos que pela atitude de comparação entre os textos de nosso corpus, estaremos aptos a entender a profundidade e a genialidade tanto de Defoe, quanto de Mozael Silveira ao adaptar o romance para a sétima arte, seguindo por vias, deliciosamente, infiéis e subversivas.

\section{Crusoe ou Crusoé: Daniel Defoe versus Mozael Silveira}

Mozael Silveira, cineasta de considerável produção no cinema brasileiro, é nome desconhecido nos meios acadêmicos, uma vez que sua linha de produção segue, prioritariamente, a criação de roteiros originais para uma época em que o cinema no Brasil seguia a estética da chanchada e da paródia, mesclando elementos de musicalidade e, inserindo, também, caracteres do carnaval nas produções que realizava.

Na adaptação que Silveira realizou do clássico de Daniel Defoe, há predominância de todos os elementos estético-estruturais citados no parágrafo anterior, acrescidos, ainda, de uma pitada satírica e uma estética que prima também pelo grotesco, ao retratar os nativos da ilha que o herói inglês atinge após o naufrágio.

O primeiro indício que aproxima as duas obras está nos títulos que figuram em ambas. Em Defoe, o título que lemos é The life and strange surprizing adventures of Robinson Crusoe of York, mariner: who lived eight and twenty years, all alone in an un-inhabited island on the cost of America, near the mouth of the great river of Oroonoque; having been cast on shore by shipwreck, where-in all the men perished but 
himself. With an account how he was at last as strangely deliver'd by pyrates. Written by himself; simplificado por Silveira em As aventuras de Robinson Crusoé. Grifos nossos.

Note-se que, na íntegra, os títulos não coincidem. O que coincide é o nome do herói: Robinson Crusoe. Isto denota, em primeira instância, o poder do mito Robinsoniano, porque a adaptação é demarcada, já de início, pelo nome do protagonista que se repete em ambos os títulos.

Todavia, devemos ressaltar que há uma espécie de corrupção linguística com relação ao termo Crusoe. Como nos afirma o narrador de Defoe, Crusoe é um nome já corrompido pela sociedade inglesa daquela época, haja vista que se trata de um nome alemão: Kreutznaer, foneticamente bem distinto de Crusoe.

[...] meu pai era um estrangeiro, de Bremen, que se estabeleceu primeiro em Hull. Ele tinha um bom estabelecimento comercial, e, após abandonar o seu negócio, passou a morar posteriormente em York, onde veio a se casar com minha mãe, cujos parentes se chamavam Robinson, uma família muito boa dessa região, e por esse motivo fui chamado de Robinson Kreutznaer; mas, por causa da habitual corruptela de palavras existentes na Inglaterra, nós agora somos chamados, não, nós nos chamamos e assinamos o nosso nome como Crusoe, e assim os meus amigos sempre me chamaram. (DEFOE, 2004, p. 22).

Tal corrupção é retrata na tela já na constituição dos créditos iniciais da obra, porque o nome do herói inglês, ao ser inserido em nossa cultura, também sofreu corrupção linguística semelhante, uma vez que os falantes da língua portuguesa (brasileira), ao não se adaptarem à estrutura fonética /K//R//U//Z//Ô/, corromperam-na para $/ \mathrm{K} / / \mathrm{R} / / \mathrm{U} / / \mathrm{Z} / / \mathrm{O} / / \mathrm{E} /$, alterando drasticamente sua sonoridade e deturpando o código hegemônico.

Essa atitude política, aproveitada por Mozael Silveira, demonstra compromisso com uma arte mais engajada; e, assim, pela propriedade paródica da adaptação em relevo, podemos verificar o que Santiago (2000) afirma ser uma atitude de tomada de consciência de nossa 
própria identidade, em termos de descolonização cultural e, ainda, independência do texto matriz.

Nessa linha de raciocinio, a problemática da mestiçagem instaurada na obra do inglês pelas relações entre Friday e o herói do romance, é também ironicamente prefigurada em países do continente europeu, como o excerto acima pode comprovar. Isto é, há uma consciência de alteridade que permeia o texto de Defoe, visto que o autor problematiza o cruzamento de origens distintas - alemã e inglesa - e, ainda, compõe seu protagonista como fruto de uma gênese humana que não mistifica os purismos de raças.

Assim, a ideia central promulgada pela fortuna critica do texto inglês, que insiste em catalogar Robinson Crusoe como uma obra que ecoa ideologias do colonizador, pode ser revista e relativizada em termos de consciência da alteridade que - pelos pequenos matizes textuais, pelas imagens fornecidas nas entrelinhas discursivas do texto e pela atitude produtiva de comparação entre as malhas heterogêneas e intertextuais que compõem a grande coletânea de adaptações (tanto cinematográficas, quanto adaptações para o gênero infanto-juvenil) pressupõe certa ironia disfarçada pela linguagem minuciosa e mimética, característica do período e do estilo individual do próprio autor. 

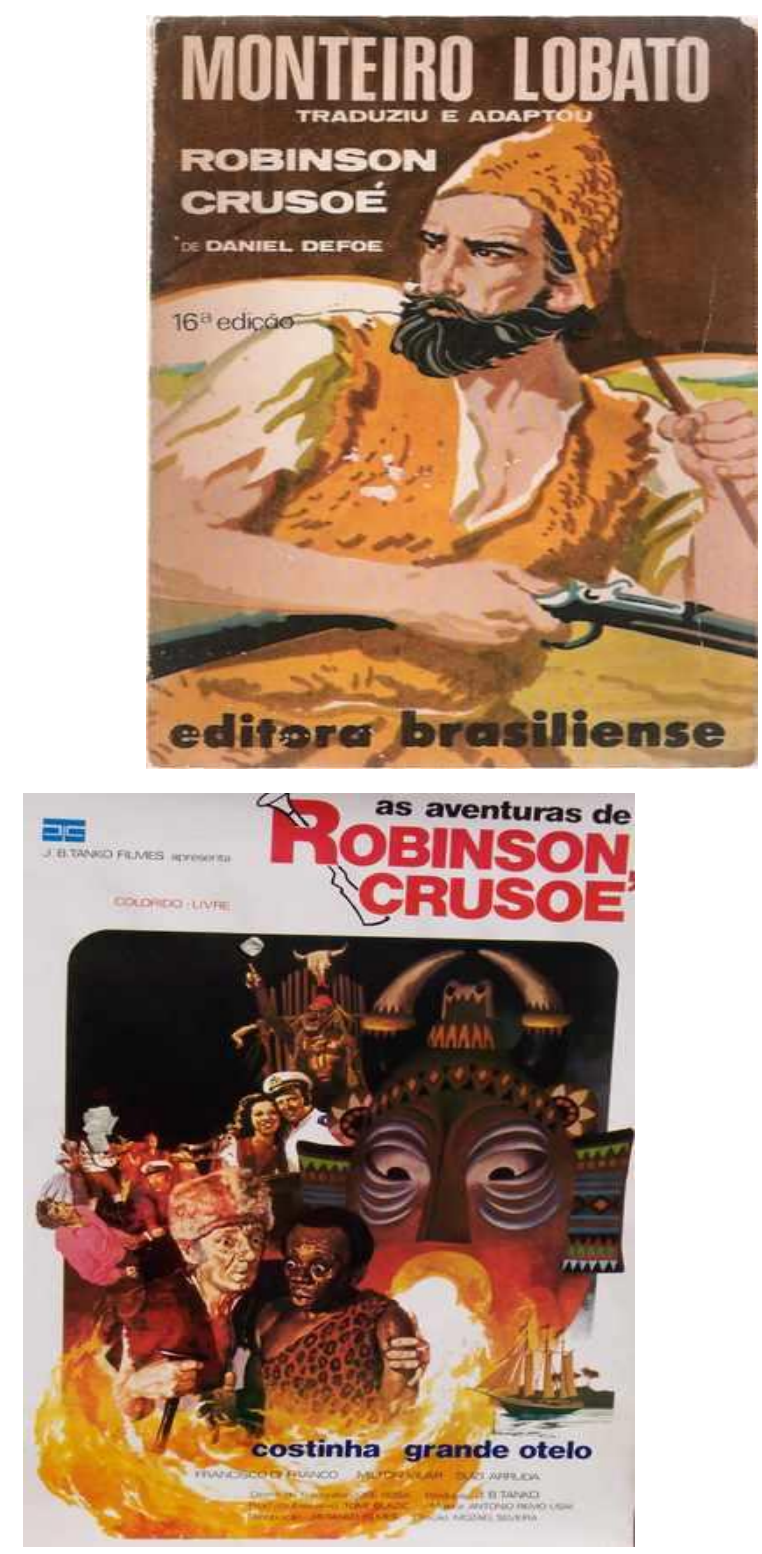

Figura I - Capa da adaptação de Lobato de Mozael Silveira

As imagens anteriores evidenciam o processo de apropriação criativa realizada por Mozael Silveira que, apontamos na esteira de Sant'Anna (2007), brinca com elementos constitutivos do romance de Defoe e, em um "efeito de linguagem que se dobra sobre si mesma como num jogo de espelhos" (p. 6), reúne signos para uma nova construção de sentidos que, por sua vez, estão imbuídos em uma crítica que refaz, na contramão, o caminho do texto clássico. Nessa ordem, podemos verificar a superposição do sagrado e do profano, em um conjunto semiótico que desintegra e, ao mesmo tempo, reintegra as 
potencialidades contra-discursivas, abrindo então novas chaves de leitura para o texto inglês. Essa atitude nos permite estabelecer uma crítica capaz de relativizar a problemática da colonização e das relações sociopolíticas que Defoe fez ecoar em pleno universo europeu do século XVIII.

Assim, o artista-adaptador, usando de sua criatividade, dá conta de transpor para a grande tela um objeto cultural autônomo e dotado de uma estética que, se à primeira vista parece infantilizada, é, na realidade, um jogo estabelecido pelo próprio realizador da adaptação ao lidar com a plasticidade do texto de Defoe, bem como com sua genialidade ao tratar de temas políticos tão caros para sua época, a saber: a Inglaterra que, no século XVIII, se lançava ao Novo Mundo como a nova rainha dos mares, em substituição à hegemonia que, dividida entre Portugal e Espanha, vigorou nos séculos XVI e XVII, dando a estes últimos o status de grandes potências ultramarinas até então.

À margem de um cinema esmagador, em termos mercadológicos cinema hollywoodiano, ideologicamente imperialista -, o cinema brasileiro então adotou estratégias contra-discursivas para inserir-se em um patamar de arte que propunha, pela paródia, estratégias estéticas que se apropriavam de clássicos buscando reescrevê-los dentro de nossa realidade multicultural e policêntrica.

Assim, como adaptador e, antes de tudo, leitor da obra a ser adaptada, Silveira adota uma postura em que o texto inglês se apresenta como um

[...] modelo produtor (e não representacional) que excita o leitor [tanto Silveira, quanto os espectadores leitores da transposição filmica] a abandonar sua posição tranquila de consumidor e a se aventurar como produtor de textos [...] a leitura em lugar de tranquilizar o leitor, de garantir seu lugar de cliente pagante na sociedade burguesa, o desperta, transforma-o, radicaliza-o e serve finalmente para acelerar o processo de expressão da própria experiência. Grifo nosso. (SANTIAGO, 2000, p. 19-20). 
E, ainda, tratando da especificidade do segundo texto, isto é, da adaptação em si, o teórico afirma:

O segundo texto se organiza a partir de uma mediação silenciosa e traiçoeira sobre o primeiro texto, e o leitor, transformado em autor, tenta surpreender o modelo original em suas limitações, suas fraquezas, em suas lacunas, desarticula-o e o rearticula de acordo com suas intenções, segundo sua própria direção ideológica, sua visão do tema apresentado de início pelo original. (SANTIAGO, p. 20).

Portanto, a adaptação assume características de crítica à obra anterior, uma crítica que, aparentemente rasa pela sua estética de comédia pastelão, disfarça a intencionalidade política pelas vias da paródia, da carnavalização e da arquitetura grotesca adotada diante de um clássico universal, e nos faz entrever minúcias da escritura de Defoe que, desconsideradas e apagadas pela fortuna crítica, são componentes de uma linha ideológica que não deve ser entendida unicamente como propulsora de uma postura dominadora e colonialista.

Deve-se considerar que, obviamente, há passagens claras no texto inglês que demonstram as injustiças apregoadas pelo sistema colonial e justificam grande parte da crítica alinhavada sobre a obra em questão.

Todavia, reiteramos, após a leitura da adaptação de Mazael Silveira e outras não apontadas neste trabalho, podemos retornar ao clássico inglês e verificar que, para o contexto de produção da obra ao qual Defoe estava imerso, o romance tinha uma intencionalidade politica mais profunda da que a maioria da crítica literária nos fornece ainda hoje.

\section{Referências bibliográficas}

ADORNO, Theodor W. Notas de literatura I. Trad. Jorge M. B. de Almeida. São Paulo: Duas Cidades \& Ed. 34, 2003. 
BELLO, Maria do Rosário Leitão Lupi. Narrativa literária e narrativa fílmica: o caso de Amor de Perdição. Tese de doutoramento. Lisboa, 2001.

BENJAMIN, Walter. Magia e técnica, arte e politica: ensaios sobre literatura e história da cultura. Trad. Sérgio Paulo Rouanet. $7^{\mathrm{a}}$ ed., São Paulo: Brasiliense, 1994.

CUNHA, Maria Zilda da. Na tessitura dos signos contemporâneos: novos olhares para a literatura infantil e juvenil. São Paulo: Humanitas \& Paulinas, 2009.

DEFOE, Daniel. A vida e as estranhas e surpreendentes aventuras de Robinson Crusoé, marinheiro de York. Trad. Domingos Demasi. Rio de Janeiro: Record, 2004.

- Robinson Crusoé: aventuras dum náufrago perdido numa ilha deserta, publicadas em 1719. Trad./Adaptação de Monteiro Lobato. Ilustração Miguel Paiva. 38ª ed. São Paulo: Brasiliense, 1994.

GUIMARÃES, César. Imagens da memória: entre o legivel e o visivel. Belo Horizonte: UFMG, 1997.

PELlEGRINI, Tania [et. al.]. Literatura, cinema e televisão. São Paulo: Senac \& Itaú Cultural, 2003.

PLAZA, Julio. Tradução intersemiótica. São Paulo: Perspectiva, 2000.

SANT' ANNA. Affonso Romano de. Paródia, paráfrase e Cia. Série Princípios. 8 $8^{\text {a }}$ ed., São Paulo: Ática, 2007.

SANTIAGO, Silviano. Uma literatura nos trópicos: ensaios sobre dependência cultural. 2a ed., Rio de Janeiro: Rocco, 2000.

SARAMAGO, José. A maior flor do mundo. Ilustração de João Caetano. São Paulo: Cia. das letrinhas, 2001. 
SOUSA, Sérgio Paulo Guimarães de. Relações intersemióticas entre o cinema e a literatura: a adaptação cinematográfica e a recepção literária do cinema. Portugal: Universidade do Minho, 2001.

STAM, Robert. A literatura através do cinema: realismo, magia e a arte da adaptação. Belo Horizonte: UFMG, 2008.

TRENT, William Peterfield. Daniel Defoe: how to know him. New York, NY: Columbia University, 2010.

WATT, Ian P. A ascensão do romance: estudos sobre Defoe, Richardson e Fielding. Trad. Hildegard Feist. São Paulo: Cia. das Letras, 1990. . Mitos do individualismo moderno: Fausto, Dom Quixote, Dom Juan, Robinson Crusoe. Trad. Mário Pontes. Rio de Janeiro: Jorge Zahar, 1997.

\section{Referências filmográficas}

SILVEIRA, Mozael. As aventuras de Robinson Crusoé. J.B. Tanko Filmes, Cor/Brasil, 1978: 90 min. 